\title{
Collision Tumor of the Stomach: A Case of an Adenocarcinoma and a Gastrointestinal Stromal Tumor
}

\author{
D.L.M. Idema ${ }^{a} \quad$ D. Daryanani ${ }^{a} \quad$ L.M.T. Sterk ${ }^{b} \quad$ J.M. Klaase ${ }^{a}$ \\ ${ }^{a}$ Department of Surgery, Medisch Spectrum Twente, and bepartment of \\ Pathology, Enschede, The Netherlands
}

\section{Key Words}

Adenocarcinoma - Collision tumor - Gastrointestinal stromal cell tumor - Gastrointestinal stromal tumor $\cdot$ Stomach

\begin{abstract}
A collision tumor of the stomach is a rare event. We report the case of a collision tumor of the stomach consisting of an adenocarcinoma and a gastrointestinal stromal tumor (GIST). This is, to our knowledge, the second report in the literature of such a case. A 71year-old man with abdominal discomfort underwent an esophagogastroduodenoscopy which revealed a tumor of the oesophagogastric junction. A total gastrectomy was performed. Histologic examination showed a mixed tumor consisting of a primary adenocarcinoma and multiple nodules of GIST. The adenocarcinoma showed both diffuse and intestinal growth, angio-invasion and metastasis to lymph nodes. The GIST tumor cells were strongly immunoreactive to CD117 and CD34. Based on mitotic index, size and cytonuclear details, the biological behavior of this GIST tumor was supposed to be benign. This case reports the rare finding of a collision tumor consisting of an adenocarcinoma and a GIST with an unknown etiology.
\end{abstract}

\section{Introduction}

Adenocarcinoma is the most common malignant gastric tumor, while gastrointestinal stromal tumors (GISTs) are relatively rare [1]. From all gastrointestinal locations, GISTs occur most frequently in the stomach (60-70\%) [1]. However, a combination of an adenocarcinoma and a GIST is a very rare finding and an actual collision of these tumors even more so. This case report is, to our best knowledge, the second report in literature. 


\begin{tabular}{l|l|l} 
Gastuenterclayy & $\begin{array}{l}\text { Pablished online: November 15, 2008 } \\
\text { D01.1159/000129707 }\end{array}$ & $\begin{array}{l}\text { ISSN 1662-0631 } \\
\text { Iww.karger.com/crg }\end{array}$ \\
\hline
\end{tabular}

\section{Case Report}

\section{Clinical Presentation}

A 71-year-old man presented with vague abdominal discomfort. Physical examination was unremarkable. Laboratory data demonstrated an ESR of $15 \mathrm{~mm} / \mathrm{h}$ (normal 1-7 mm/h), a hemoglobin level of $6.5 \mathrm{mmol} / \mathrm{l}$ (normal $8.5-11.0 \mathrm{mmol} / \mathrm{l})$, thrombocytes $341 \times 10^{9}$ (normal 150-400 $\times 10^{9}$ ), leukocytes $8.9 \times 10^{9}\left(\right.$ normal $\left.4.0-10.0 \times 10^{9}\right)$. Renal and liver function tests were normal. Esophagogastroduodenoscopy revealed a tumor at the oesophagogastric junction from which biopsies were taken. Histologic examination revealed an adenocarcinoma.

Chest X-ray did not show any signs of metastasis. Endosonography showed an irregular course of the gastric wall where it was adjacent to the liver, not excluding possible invasive growth into the liver and thus suggesting the possibility of a T4 carcinoma. Sonography of the neck region and the abdomen showed no lymph node involvement or signs of metastasis to other organs. Primary surgery consisting of a total gastrectomy with Roux-en-Y esophagojejunostomy was performed. Except from a postoperative septic period as a result of a spondylodiscitis, which was successfully treated with antibiotics, the patient was postoperatively discharged in clinically good condition after six weeks. Two and a half years after the total gastrectomy the patient developed pleural effusion due to adenocarcinoma metastases and died shortly thereafter.

\section{Pathologic Findings}

The resected specimen consisted of a totally resected stomach with en bloc part of the distal oesophagus. Alongside the lesser curvature there was a tumor, measuring $5 \times 4 \times 2.5 \mathrm{~cm}$. On cut section the tumor invaded through the muscularis propria into the fat of the omentum minus. Microscopically the tumor consisted of both a conventional adenocarcinoma and tumor nodules composed of cells with another phenotype. Most of the adenocarcinoma was found in the submucosa, but focally the adenocarcinoma invaded all layers of the gastric wall into the outer serosal surface or perigastric fat. This tumor was composed of a combination of intestinal, gland-forming growth and a diffuse, poorly adhesive, often signet-ring morphology. There was also angioinvasive growth. The proximal and distal resection margins were free of tumor. Metastasis was found in 5 of the 8 resected lymph nodes.

The other tumor was found multifocal in the submucosa, muscularis propria and subserosa. It consisted of nodules up to $6 \mathrm{~mm}$ composed of spindle cells with little cytonuclear polymorphism and with no significant amount of mitosis ( $<5 / 50 \mathrm{HPF}$ ) (fig. 1a). These cells expressed high levels of CD117 (fig. 1b) and CD34, while other stromal cell markers like S100, smooth muscle actin and desmin were not expressed. It was therefore concluded that these tumor nodules were GIST. Figure $1 \mathrm{c}$ shows the actual 'collision' between the adenocarcinoma and the GIST.

\section{Discussion}

GISTs were first mentioned in 1983 by Mazur and Clark [2]. These tumors are the most common mesenchymal tumors in the digestive tract and are thought to originate either from the stem cells that differentiate towards interstitial cells of Cajal, or directly from interstitial cells of Cajal $[3,4]$. Small GISTs are often detected incidentally during surgery for other reasons, or are detected during gastroscopy [1]. In general, GISTs can be differentiated from other tumors made up from spindle cells and/or epitheloid cells by expressing CD117 (c-kit) and CD34 in 50-80\% of cases [3, 4]. The KIT gene codes for ckit protein which activates a tyrosine kinase after binding with a stem cell factor. $90 \%$ of GISTs have a mutation in the KIT oncogene, but $10 \%$ miss this mutation [4]. These sometimes CD117-negative tumors often have a mutation in the platelet-derived growth factor receptor a (PDGFRa).

Nowadays, the prognosis and biological behaviour of GIST depends on a combination of two criteria: the size of the tumor and the mitotic index [1]. Surgical resection is the 
primary treatment for GIST. Approximately $70-85 \%$ of patients have a complete resection, but overall five-year survival is only $50 \%$, because of the tendency of the GIST to metastasize or to recur. Since 2002 a new therapy, imatinib mesylate, is developed to treat this kind of malignancies when metastasized or irresectable. This is a tyrosine kinase inhibitor and demonstrates dramatic effects in the majority of patients. $80 \%$ of patients have either a response or stable disease with imatinib treatment [5].

After several years of treating patients with imatinib, resistance has developed. Approximately $50 \%$ of patients do not respond after two years of treatment [6]. Possibly the kind of KIT gene mutation has an effect on the development of resistance and the tumor response on imatinib [4].

Collision tumors are defined as morphologically different neighboring neoplasms that do not intermingle [7]. The development of gastric collision tumors is very rare. In the English literature we found one case report describing the occurrence of an adenocarcinoma mixed with a GIST [8]. Several cases describing various other combinations of tumor have been reported [7, 9-11]. Various hypotheses have been proposed about synchronous occurrence of GIST and adenocarcinoma. They considered whether or not such an association was incidental or whether the two lesions were connected by a causal relationship. Some articles suggest that gene mutations or a single carcinogenic agent might interact with two neighboring tissues, inducing the development of tumors of different histiotypes in the same organ, but no evidence of this last hypothesis has yet been found $[8,10]$. Both tumors have different precursor cells and molecular make-up, and if there were a single carcinogen, these types of tumor would probably be diagnosed more often.

In this case the diagnosis of GIST was made based on the tumor phenotype in combination with immunoreactivity to CD117 and CD34. The GIST was presumed to be benign due to the low mitotic count, size and to a lesser extent the low degree of cellularity and cellular polymorphism. Although multicentricity is often considered a sign of malignancy, in this case, only very small nodules with no histological signs of malignant clinical behavior were present. Therefore it was expected that in this case the prognosis would most probably be determined by the adenocarcinoma component as this tumor penetrated the entire gastric wall into the serosa, had invaded blood vessels and showed lymph node metastasis.

\section{Conclusion}

We present a patient suffering from a collision tumor consisting of an adenocarcinoma originating from the gastric mucosa and a GIST that was presumed to behave in a benign fashion. As shown by the adenocarcinoma metastasis in the pleural effusion and death two and a half years after surgery, the patient's prognosis was determined by the adenocarcinoma component. Two primary tumors of the stomach are a rare event. However, an actual collision of both an epithelial adenocarcinoma and a GIST is exceedingly rare and as far as we know now, both with different and unknown etiology. 


\begin{tabular}{r|l|l|l} 
Case Reports $/$ h & $\begin{array}{l}\text { Case Rep Gastroenterol 2008;2:456-460 } \\
\text { D01: 10.1159/000129707 }\end{array}$ & Published online: November 15, 2008 & $\begin{array}{l}\text { O 2008 S. Karger AG, Basel } \\
\text { ISSN 1662-0631 } \\
\text { www.karger.com/crg }\end{array}$ \\
\hline
\end{tabular}

Fig. 1. a Gastric wall: hematoxylin and eosin. Tumor nodule in relation to the muscularis propria. The tumor cells are composed of spindle cells and partly storiform, show moderate cytonuclear polymorphism without obvious mitoses or necrosis. $\mathrm{M}=$ Mucosa; $\mathrm{T}=$ tumor; $\mathrm{MP}=$ muscularis propria. b Gastric wall: immonuhistochemistry. Gastrointestinal stromal tumor showing CD117 expression. Insert: Detail of tumor cells with the aspects described in figure 1. M = Mucosa; $\mathrm{T}=$ tumor; $\mathrm{MP}=$ muscularis propria. c Gastric wall: hematoxylin and eosin. Collision of the infiltrating adenocarcinoma originated from the gastric mucosa and the GIST. A = Adenocarcinoma; $\mathrm{G}=$ GIST; $\mathrm{C}=$ calcification.
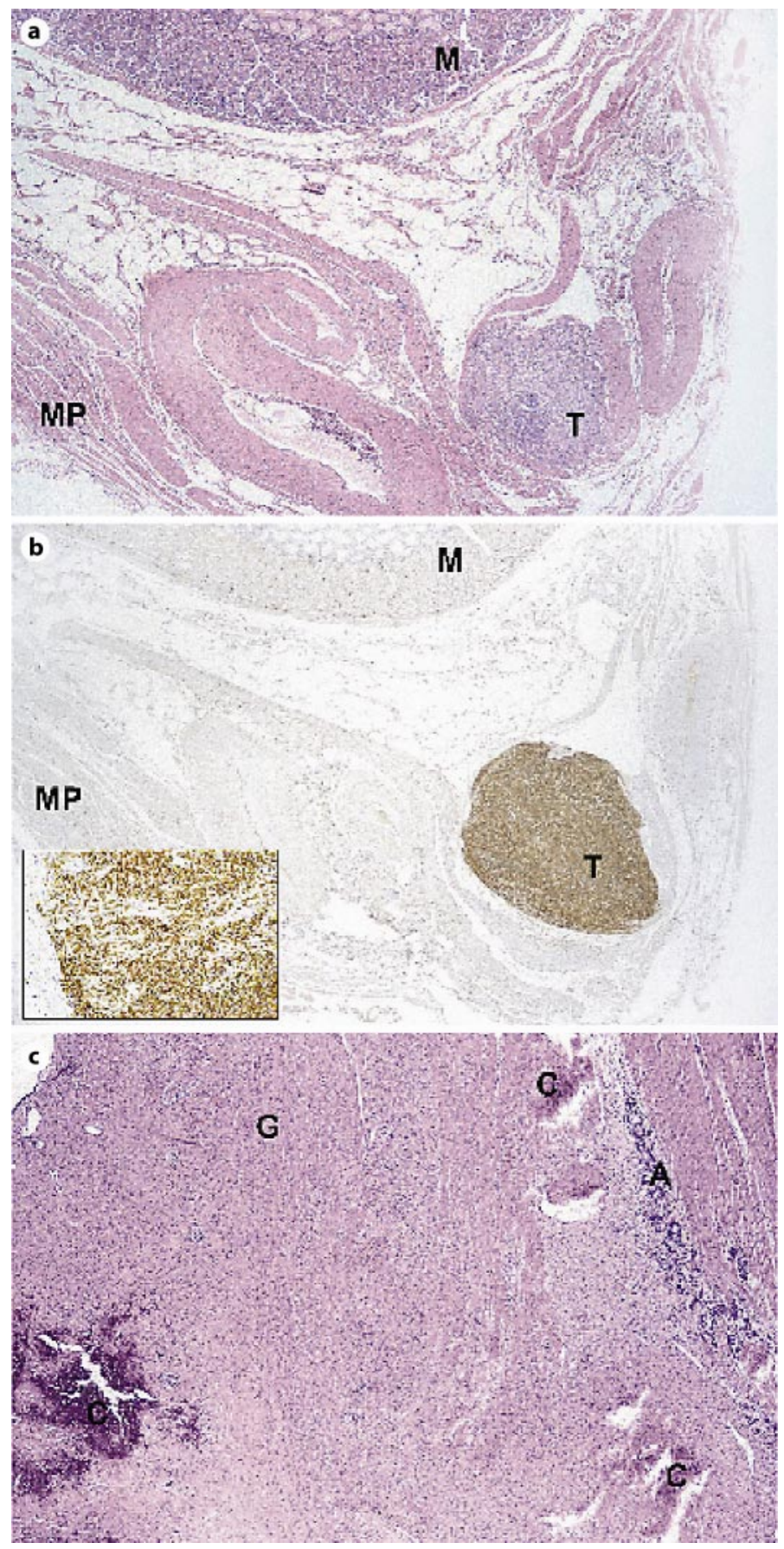


\section{References}

1 Miettinen M, Lasota J: Gastrointestinal stromal tumors. Review on morphology, molecular pathology, prognosis and differential diagnosis. Arch Pathol Lab Med 2006;130:1466-1478

2 Mazur MT, Clark HB: Gastric stromal tumors: reappraisal of histogenesis. Am J Surg Pathol 1983;7:507-519.

3 Miettinen M, Sarlomo-Rikala M, Lasota J: Gastrointestinal stromal tumors: Recent advances in understanding of their biology. Hum Pathol 1999;30:12131220.

4 Van der Zwan SM, DeMatteo RP: Gastrointestinal stromal tumor: 5 years later. Cancer 2005;104:1781-1788.

5 Verweij J, Van Oosterom A, Blay JY, et al: Imatinib mesylate (STI-571 Glivec ${ }^{\circledR}$, Gleevec $^{\mathrm{TM}}$ ) is an active agent for gastrointestinal stromal tumors, but does not yield responses in other soft-tissue sarcomas that are unselected for a molecular target: Results from an EORTC Soft Tissue and Bone Sarcoma Group phase II study. Eur J Cancer 2003;39:2006-2011.

6 Demetri GD, Von Mehren M, Blanke CD, et al: Efficacy and safety of imatinib mesylate in advanced gastrointestinal stromal tumors. New Engl J Med 2002;347:472-480.

7 Klaase JM, Hulscher JBF, Offerhaus GJA, et al: Surgery for unusual histopathologic variants of esophageal neoplasms: A report of 23 cases with emphasis of histopathologic characteristics. Ann Surg Oncol 2003;10:261-267.

8 Liu SW, Chen GH, Hsieh PP: Collision tumor of the stomach. A case report of mixed gastrointestinal stromal tumor and adenocarcinoma. J Clin Gastroenterol 2002;34:332-334.

9 Bircan S, Candir O, Aydin S, et al: Synchronous primary adenocarcinoma and gastrointestinal stromal tumor in the stomach: A report of two cases. Turk J Gastroenterol 2004;15:187-191.

10 Maiorana A, Fante R, Cesinaro AM, Fano RA: Synchronous occurrence of epithelial and stromal tumors in the stomach. A report of 6 cases. Arch Pathol Lab Med 2000;124:682-686.

11 Sailors JL, French SW: The unique simultaneous occurrence of granular cell tumor, gastrointestinal stromal tumor, and gastric adenocarcinoma. Arch Pathol Lab Med 2005;129:e121-e123. 